\title{
Artigos
}

\section{O diagnóstico tardio na perspectiva do itinerário terapêutico: grau 2 de incapacidade física na hanseníase}

Late diagnosis under the perspective of therapeutic itineraries: level 2 physical disabilities in Hansen's disease (abstract: p. 18)

El diagnóstico tardío desde la perspectiva del itinerario terapéutico: grado 2 de discapacidad física en la enfermedad de Hansen (resumen: p. 18)

\section{Mirella Chaves Laragnoit Hespanhol(a)}

>mhespanhol@unifesp.br>

\section{Sidney Marcel Domingues ${ }^{(b)}$}

<sidusp@gmail.com> iD

Lúcia da Rocha Uchôa-Figueiredo ${ }^{(c)}$

<uchoa.lucia@unifesp.br> (a) Terapeuta Ocupacional. Rua Kátia Cristina Quedas Nunes, 91, Vila Caiçara. Praia Grande, SP, Brasil, 11707-070.

(b) Curso de Medicina,

Universidade Municipal de São Caetano do Sul, Campus Bela

Vista. São Paulo, SP, Brasil.

(c) Programa de Pós-Graduação

Interdisciplinar em Ciências da

Saúde, Universidade Federal de

São Paulo. Santos, SP, Brasil.

Destacam-se casos novos de hanseníase com grau de incapacidade física 2 (GIF 2) que demonstram a ineficiente detecção oportuna. 0 artigo é um relato de casos e propõe analisar o diagnóstico tardio sob a perspectiva do itinerário terapêutico (IT), com base em um estudo qualitativo. 0 cenário foram dois municípios da Região Metropolitana da Baixada Santista: Praia Grande e São Vicente. Realizou-se análise documental e entrevista em profundidade com quatro participantes. 0 material foi submetido à análise de conteúdo e definiram-se as categorias temáticas: cuidado em saúde; corpo na hanseníase; incapacidades na hanseníase; e diagnóstico tardio. Revelaram-se intrincados itinerários terapêuticos, marcados pela fragilidade do cuidado com erro e atraso no diagnóstico, que potencializaram os riscos individuais e coletivos e impactaram negativamente o cotidiano dos sujeitos.

Palavras-chave: Saúde pública. Hanseníase. Pessoa com deficiência. Diagnóstico tardio. Itinerário terapêutico. 


\section{Introdução}

A hanseníase é uma doença transmissível, que tem como agente etiológico o mycobacterium leprae e se manifesta por meio de sinais e sintomas dermatoneurológicos. É considerada um problema de saúde pública por ser incapacitante e causar comprometimento no âmbito psicossocial ${ }^{1,2}$.

O Brasil é um país endêmico e apresenta alta carga para a hanseníase, sendo o segundo com o maior número de novos casos registrados no mundo, não atingindo as metas de eliminação determinadas pela Organização Mundial de Saúde (OMS) ${ }^{3,4}$. Em 2016, foram notificados 25.218 casos e embora haja redução de prevalência da doença, nota-se um contínuo registro de casos novos com distribuição heterogênea nas regiôes do país, atingindo assim um número significativo de pessoas com percentuais expressivos de grau de incapacidade física 2 (GIF 2) identificado no diagnóstico ${ }^{4,5}$.

É importante ressaltar que, além da predisposição individual e do contato com um doente sem tratamento, a hanseníase é uma doença sensível à vulnerabilidade social e prevalente nas populaçốes que vivem em condiçôes precárias de vida e saúde, realidade dos países em desenvolvimento, e incorpora o rol das doenças tropicais negligenciadas ${ }^{5,6}$.

O diagnóstico da hanseníase é sobretudo clínico e são indispensáveis a avaliação dos sinais e dos sintomas, o histórico de antecedentes e o exame físico completo ${ }^{4}$.

Segundo o Ministério da Saúde (MS), o grau de incapacidade física (GIF) é uma medida que indica a existência de perda da sensibilidade protetora e/ou deformidade visível em consequência de lesão neural e norteia o desenvolvimento das práticas de prevenção de incapacidades e da reabilitação. É um indicador epidemiológico utilizado na avaliação do programa de vigilância de hanseníase, determinando a precocidade do diagnóstico e o sucesso das atividades que visam à interrupção da cadeia de transmissão ${ }^{7}$. A avaliação de incapacidade que identifica e descreve as deficiências sensório-motoras nos olhos, mãos e pés se classifica em GIF 0, 1 e 2, sendo o grau 2 determinado pela presença de deficiências visíveis nos segmentos avaliados?

Compreende-se, portanto, que as pessoas diagnosticadas com hanseníase e GIF 2 têm o diagnóstico tardio. As deficiências físicas adquiridas são consideradas as principais causas de estigma e isolamento social e representam forte impacto econômico e psicológico na vida das pessoas atingidas ${ }^{7,8}$. Por isso, com a finalidade de reduzir a carga da hanseníase, foram traçadas metas de redução do GIF 2 nos âmbitos nacional e mundial, com incorporação de açôes estratégicas que visam garantir o cuidado integral ${ }^{3,9}$.

Mediante o exposto, o objetivo deste artigo é analisar o diagnóstico tardio sob a perspectiva do itinerário terapêutico (IT) de casos emblemáticos. Segundo Alves ${ }^{10}$, o IT é um dos conceitos centrais nos estudos socioantropológicos em saúde, sendo termo utilizado para designar as atividades desenvolvidas pelos indivíduos na busca de tratamento para doença e/ou aflição. O IT é, portanto, uma forma de engajamento em uma dada situação e requer novos aprendizados e habilidades ${ }^{10-12}$. 


\section{Método}

Tratou-se de relato de casos com base em estudo qualitativo, recorte da pesquisa de mestrado intitulada "Itinerário terapêutico de pessoas com hanseníase e deficiência adquirida”"13, desenvolvida no Programa de Pós-Graduação Ensino em Ciências da Saúde, modalidade profissional, da Universidade Federal de São Paulo (Unifesp) campus Baixada Santista.

A pesquisa foi desenvolvida no período de 2017 a 2019, e os participantes foram quatro pacientes diagnosticados com hanseníase e GIF 2, casos notificados em dois serviços especializados em hanseníase em 2016. Foram cenários: na Praia Grande, o Centro de Referência e Atendimento à Tuberculose e Hanseníase (CRATH); e em São Vicente, o Centro de Atendimento à Tuberculose e Hanseníase (CATH), ambos localizados na Região Metropolitana da Baixada Santista (RMBS), pertencentes ao Grupo de Vigilância Epidemiológica (GVE XXV - Santos), do estado de São Paulo, que no ano de 2006 atingiu a meta de eliminação da doença.

Os dados epidemiológicos do ano pesquisado informaram que na Praia Grande foram registrados treze casos novos em 2016, dois com GIF 2, correspondendo a $15,38 \%$ dos casos. Em São Vicente foram registrados doze casos novos, dois com GIF 2, correspondendo a $16,66 \%$ dos casos.

Os dados da pesquisa foram obtidos por meio de entrevista em profundidade e análise documental de fontes secundárias, submetidos à análise de conteúdo, categoria temática, com enfoque no IT.

Os participantes assinaram o Termo de Consentimento Livre e Esclarecido (TCLE) e a pesquisa foi aprovada pelo Comitê de Ética em Pesquisa da Unifesp e Plataforma Brasil sob parecer n. 3.272.503/2019.

\section{Resultados e discussão}

\section{Caracterização dos participantes}

Os participantes foram quatro pacientes diagnosticados com hanseníase e GIF 2, casos notificados em dois serviços especializados em hanseníase em 2016 em dois municípios da RMBS: Praia Grande e São Vicente. As características sociodemográficas, naturalidade, escolaridade, situação profissional e renda no momento da pesquisa estão apresentadas no Quadro 1. 
Quadro 1. Características sociodemográficas. Coleta de dados realizada no ano de 2018.

\begin{tabular}{|c|c|c|c|c|}
\hline IDENTIFICAÇÃO & LUIZ & AMÉLIA & JOSÉ & JOÃO \\
\hline Sexo & Masculino & Feminino & Masculino & Masculino \\
\hline Ano de nascimento & 1970 & 1957 & 1973 & 1973 \\
\hline Naturalidade & São Vicente/SP & Tabaraí/SP & Santos/SP & Umari/CE \\
\hline Escolaridade & $\begin{array}{l}\text { Fundamental } \\
\text { incompleto }\end{array}$ & Fundamental completo & Ensino médio completo & $\begin{array}{l}\text { Fundamental } \\
\text { incompleto }\end{array}$ \\
\hline Estado civil & Solteiro & Casada & Casado & Solteiro \\
\hline Etnia & Branca & Parda & Branca & Negro \\
\hline Município de tratamento & São Vicente & Praia Grande & São Vicente & Praia Grande \\
\hline Profissão & $\begin{array}{l}\text { Operador de } \\
\text { roçadeira }\end{array}$ & Balconista & Repositor & Vendedor autônomo \\
\hline $\begin{array}{l}\text { Situação trabalhista no } \\
\text { diagnóstico }\end{array}$ & Trabalhando & Trabalhando & $\begin{array}{l}\text { Afastado por outro } \\
\text { diagnóstico }\end{array}$ & Trabalhando \\
\hline $\begin{array}{l}\text { Situação trabalhista no } \\
\text { momento da pesquisa }\end{array}$ & $\begin{array}{l}\text { Aposentado } \\
\text { por invalidez }\end{array}$ & $\begin{array}{l}\text { Aposentada } \\
\text { por invalidez }\end{array}$ & $\begin{array}{l}\text { Aposentado } \\
\text { por invalidez }\end{array}$ & Trabalhando \\
\hline $\begin{array}{l}\text { Renda mensal } \\
\text { (base salário mínimo) }\end{array}$ & \pm 1.7 & \pm 2.3 & \pm 1.2 & \pm 1.9 \\
\hline
\end{tabular}

Fonte: Unifesp, Hespanhol (2019)

\section{Categorias temáticas}

Os resultados serão apresentados em quatro categorias: cuidado em saúde, corpo na hanseníase, diagnóstico tardio e incapacidades em hanseníase ${ }^{13}$. Para a identificação das falas foram utilizados nomes fictícios: Luiz, Amélia, José e João.

\section{O cuidado em saúde: experiências do adoecimento e uso dos serviços de saúde}

Sobre a experiência do adoecimento, nota-se que a compreensão dos participantes sobre cuidados em saúde diz respeito ao acesso ao profissional médico. A busca foi motivada por uma perturbação no estado geral, ou seja, prevalece o entendimento da saúde como ausência de doença: "É, eu nunca dei muita importância. Eu comecei a dar depois que eu comecei a sentir muita dor no pé” (Amélia).

A vulnerabilidade social interfere nas dimensóes da vida e no que é tocante ao cuidado em saúde ${ }^{6}$, conforme descrito por Luiz, no período em que vivia em situação de indigência: "A saúde eu não me preocupava, porque a droga em si complementava. Eu não sentia sintomas, porque a cocaína amortece...” (Luiz). 
Entre os participantes, predominou a população masculina. Tal realidade assemelha-se à epidemiologia com maior incidência de casos, além de refletir a ausência de cuidado em saúde para essa população específica ${ }^{14}$.

Sobre o disparador para o cuidado em saúde, nota-se a necessidade dos indivíduos de superar as rupturas que a doença causa. Destaca-se o agir leigo ${ }^{11}$ :

As pessoas movem-se por suas necessidades de saúde, entendidas no seu sentido mais ampliado, incluindo aí a conservação da autonomia no modo de andar a vida, a busca de vínculo e cuidado, o bem-estar, o fim da dor, a alegria de viver, a beleza. (p. 93)

Os participantes não tinham como referência a Atenção Básica $(\mathrm{AB})$; de certa forma, não reconheciam os recursos e não os utilizavam, como se observa nas falas:

Não procurava. Fui umas vezes, por conta de conseguir dias para afastar. (Luiz)

Eu ia e não ia, ia por outra situação, medir a pressão ou um ginecologista. (Amélia)

Postinho, pra ser sincero, eu acho um pouco complicado. (José)

Não, raramente. Não precisava, não tinha motivo, não tinha por que ir. (João)

A ausência de vínculo com um serviço de saúde impossibilitou a observação das necessidades em saúde. Segundo Cecílio ${ }^{15}$, "as necessidades em saúde são socialmente e historicamente determinadas/construídas, elas só podem ser captadas e trabalhadas em sua dimensão individual” (p. 118).

Nas trajetórias assistenciais analisadas, observou-se que a $\mathrm{AB}$ forneceu guias, e isso ocorreu em função da prática de regulação para acesso ao serviço especializado. No entanto, o encaminhamento deve ser entendido como um procedimento de acompanhamento, uma vez que os serviços pesquisados funcionam com portas abertas, embora incluídos na categoria de especialidades.

\section{O corpo na hanseníase: as modificações funcionais e estéticas como condição disparadora para a busca do cuidado formal em saúde}

Segundo Ferreira ${ }^{16}$, para os especialistas em saúde destaca-se a importância dos estudos sobre o corpo doente, considerado como depositário de processos biológicos, indicadores de saúde e doença. Entende-se assim o corpo como signo. Dessa forma, determinadas mensagens emitidas pelo corpo, sintomas experienciados e sinais observados no exame clínico-médico passam a representar um significado: a doença. $\mathrm{O}$ sintoma, diferentemente 
do sinal, é o caráter invisível da doença, pois retrata sensações que o indivíduo experimenta e expressa. Já o sinal é a manifestação objetiva e faz parte do aspecto visível da doença, observado por meio do exame físico ${ }^{16}$.

Nota-se que os sinais e sintomas da hanseníase foram identificados, com percepção das alteraçôes funcionais e estéticas, antes da revelação diagnóstica. Foram citados manchas, caroços e áreas hipoestésicas na pele; dormência, fraqueza muscular e dor tipo choque em membros superiores (MMSS) e inferiores (MMII), com comprometimentos das atividades de vida diária (AVD) e laborais.

Para compreender o disparador para a busca de cuidado em saúde, foi relacionada a avaliação física realizada no diagnóstico com a percepção do participante sobre seu corpo.

O participante Luiz foi encaminhado como caso suspeito de hanseníase, com diagnóstico de polineuropatia periférica dos MMSS. Na anamnese, relatou há três anos dor tipo choque em membro superior direito (MSD). Na avaliação física, apresentou infiltração difusa na face; mão direita em garra; em membro superior esquerdo (MSE), neurite ulnar, atrofia muscular e ferimento na mão; no membro inferior direito (MID), diminuição da força muscular, dor na palpação do nervo tibial e fibular, calosidades, cicatriz de mal perfurante plantar (MPP) e edema em membros inferiores (MMII).

No caso de Luiz a doença manifestou-se com áreas hipoestésicas na pele e comprometimento neurológico, e o disparador para o cuidado foram as alteraçôes funcionais:

As mãos e os pés. O problema mais seriam as dormências no corpo, nas mãos. Não teve manchas, só dormências. E as dores começaram a incomodar. [...] A principal coisa foi porque eu estava vendo que a minha mão estava começando a atrofiar, e a outra a ter dormências, câimbras, então eu falei, eu vou. (Luiz)

Amélia relatou que em 2013 surgiram manchas vermelhas no corpo; foi ao médico dermatologista em uma clínica de saúde popular e foi diagnosticada com alergia. Entretanto, em 2015, notou dormência em seus braços e pernas. Na avaliação física, apresentou infiltração difusa e madarose supraciliar; no MSD, hipoestesia em antebraço; em MID, ausência de sensibilidade protetora; e no membro inferior esquerdo (MIE), neurite tibial, com força muscular diminuída e dedos em garra.

No caso de Amélia a alteração estética era o principal incômodo, e a alteração funcional foi percebida em uma tarefa cotidiana:

Foi a pele que deu uns caroços, com secreção. E começou a adormecer o pé, aí aqui um pouco (mostrando o antebraço), aqui (cotovelo), tanto que eu fui pegar a panela e fiquei por um tempo sem ir para o fogão, porque eu quase me queimo[...]. (Amélia)

E apesar de se submeter a tratamento, percebia a piora dermatológica: 
Foi antes de 2016, eu fiz tudo isso e não descobri. Eu fiquei dois anos afastada, como alergia [...] aí começou a sair um monte de caroço, tanto que eu tenho todas as marcas, tinha secreção e eu comecei a perceber que a minha pele foi envelhecendo. A médica dizia que era alergia e eu achando que eram os remédios. (Amélia)

A presença de deformidade na face passou a ser notada; já as alteraçôes funcionais relacionadas à hanseníase foram identificadas apenas no diagnóstico:

Um dia, um conhecido meu, falou assim pra mim: você hoje olhou no espelho? Você viu sua orelha como é que tá? Eu falei o que é tem minha orelha? A minha orelha tava parecendo orelha de coelho, já deformando. Na mesma hora que eu tava com o cabelo amarrado, eu soltei. Ele foi embora e eu corri para o espelho e tava mesmo [...] (Amélia)

Por sua vez, José relatou rachaduras em seus pés em 2013, que se transformaram em feridas. Cinco meses antes do diagnóstico, notou manchas avermelhadas e hipoestésicas pelo corpo. O participante relatou que fez exame de contato em 2002 (mãe fez tratamento de hanseníase), porém não realizou a revacinação de BCG, conforme preconizado, demonstrando a fragilidade do controle de contatos.

Os contatos domiciliares e consanguíneos dos doentes apresentam maior suscetibilidade para o adoecimento, exigindo vigilância qualificada e ativa para controle da doença, com um olhar ampliado para além do indivíduo diagnosticado ${ }^{8}$.

$\mathrm{Na}$ avaliação física, José apresentou dor na palpação do nervo ulnar em MSD; em MIE, neurite do nervo tibial e fibular; em MMII, edema, ausência de sensibilidade protetora e mal perfurante plantar bilateral. Com histórico de graves problemas ortopédicos, as alterações funcionais eram associadas a esse comprometimento:

Era coluna, as pernas e os braços. Então que nem quando a gente dorme em cima dele, sem sensibilidade nenhuma e choque, a perna também dava choque, ainda dá, muitas coisas os médicos associa a coluna. (José)

A alteração funcional foi notada ao andar de bicicleta. Todavia, o diagnóstico anterior e a rotina laboral dificultaram a relação dessas queixas com a hanseníase:

Eu andando um dia de bicicleta eu senti o meu pé amortecido, aí de lá pra cá comecei a reparar esses problemas. De lá pra cá foi associando, porque estava doendo a coluna, a gente tá no sangue quente no trabalho, nós nem vê. (José)

No entanto, a alteração estética foi relevante, uma vez que as outras queixas eram consideradas ortopédicas e relacionadas à causa somente após o diagnóstico: 
Então porque as dores foram aumentando, a dormência e esse buraco no pé. Aí foi que quando apareceu essa mancha, aí o pessoal falava é impinge, aí como não sumia eu resolvi procurar. (José)

Por fim, João apresentou lesão hipocrômica na pele em MSD em 2011. Em 2015, surgimento de manchas eritematosas em seu corpo e dormência no pé esquerdo. $\mathrm{Na}$ avaliação física apresentava infiltração difusa na face e no corpo; em MID, dor e espessamento na palpação do nervo tibial e fibular; pé caído em MIE, com ausência de sensibilidade protetora nos pés.

As manchas disseminadas em todo o corpo foram desvalorizadas em atendimento médico com especialista em clínica de saúde popular:

Tinha manchas no braço, na barriga, praticamente no corpo todo: [...] Através das manchas e da minha cliente, se fosse ela também eu não ia descobrir, porque eu fiz exame particular e não deu nada [...] (João)

A percepção de uma pessoa tratada possibilitou a hipótese diagnóstica da doença:

[...] descobri mesmo através de uma cliente minha que viu as manchas e falou que do jeito que eu tava parecia que era hanseníase (João).

No diagnóstico os participantes apresentavam deficiências adquiridas: Luiz apresentava mão em garra; Amélia, pés em garra; José, mal perfurante plantar bilateral; João tinha o pé caído. Essas deficiências influenciavam negativamente o desempenho das atividades cotidianas mesmo antes do diagnóstico, gerando assim incapacidades.

Incapacidades em hanseníase: o comprometimento do cotidiano pela deficiência adquirida

De acordo com a Secretaria de Vigilância em Saúde (SVS), a hanseníase gera incapacidades físicas que afetam a rotina, o desempenho da AVD e do trabalho e comprometem a qualidade de vida de diversas maneiras, acarretando problemas psicossociais?

Os sintomas descritos possibilitaram identificar que a doença gerou impactos no cotidiano mesmo antes do diagnóstico. Todos relataram alterações das estruturas do corpo e funçôes, com limitação de atividades e restrição de participação social.

O participante Luiz destacou as dificuldades na realização de AVD, com dificuldade para realizar preensão de objetos em decorrência da mão em garra:

Porque a mão atrofiada já perdia uma parte de vamos supor, para escrever dificulta às vezes pegar uma colher, um copo, às vezes cai da mão não sinto. (Luiz)

O impedimento para o trabalho ocorreu pela intensidade da dor. No caso de Luiz, esse fator foi fundamental para a identificação do problema de saúde: 
É, eu ia trabalhar e não aguentei trabalhar. A máquina não é uma máquina que você sobe em cima dela. Você tem que andar com ela pendurada do lado ou nas costas. (Luiz)

Já Amélia revelou nervosismo e vergonha, assim viveu em isolamento para evitar a exposição e a especulação sobre sua saúde, demonstrando preocupação com a transmissibilidade:

Eu não tirava por vergonha... era devido o que eu tinha no corpo, por eu trabalhar na loja eu tinha medo que as pessoas vissem e falassem, ela tá com uma doença que vai pegar”. (Amélia)

O participante José relatou as dificuldades em permanecer ativo no trabalho:

Era muito ruim, porque o serviço já é um pouco pesado, só que tinha que trabalhar. (José)

A prática do lazer também foi relatada por José, que citou prejuízo antes mesmo do diagnóstico:

Eu deixei de fazer bastante coisa que nem assim. Uma coisa que eu gosto que é mesmo de jogar um futebol, já faz tempo que eu não jogo. (José)

Apesar da presença de incômodos físicos, João relatou a manutenção da atividade laboral:

Eu trabalhava, mas só que incomoda, aquelas manchas no corpo ficavam doídas, ficava doendo um pouco no corpo, incomoda um pouco. (João)

Considerou-se nesta pesquisa o trabalho como exercício de uma ocupação com remuneração, classificado como formal e informal. É importante destacar que se observou a situação trabalhista no diagnóstico e no momento da pesquisa. No diagnóstico identificouse que três participantes trabalhavam; um estava afastado com outro diagnóstico clínico ${ }^{17}$.

No momento da entrevista, porém, cerca de um ano e meio após o diagnóstico, três dos quatro participantes encontravam-se aposentados por invalidez. Além disso, todos apresentaram laudo médico na perícia do Instituto Nacional de Seguridade Social (INSS), com diagnóstico de hanseníase e GIF 2.

O único participante que continuava trabalhando era trabalhador informal, o que impediu o afastamento laboral, porém não se sentia incapacitado ao adequar a carga de trabalho de acordo com sua condição física. A informalidade é um marcador de desigualdades e traz como consequência a falta de acesso aos mecanismos de proteção social vinculados à formalização, a direitos básicos como a remuneração pelo salário mínimo e aposentadoria ${ }^{17}$. 
Com idade entre 45 e 61 anos, todos os participantes tiveram a capacidade laborativa afetada pelos comprometimentos da doença. Reconhecendo o trabalho como uma ocupação humana, que além de suprir a subsistência pode proporcionar a satisfação pessoal, a aposentadoria precoce traz modificaçóes na rotina e projetos de vida.

\section{Diagnóstico tardio: o impacto do desconhecimento e da desinformação na manutenção da hanseníase como doença negligenciada}

$\mathrm{Na}$ avaliação do conhecimento sobre a hanseníase, observou-se desconhecimento total sobre a doença e suas possíveis complicações, como exposto nas seguintes falas:

Não mesmo porque nunca procurei hanseníase, eu só fiquei, sabia que era tipo quando as pessoas tinham aquelas manchas no corpo, perguntei o que é isso: ah, é hanseníase, mas até então eu não sabia que dava no nervo, dá no sangue. (Luiz)

Eu nem sabia o que era hanseníase, não conhecia o que era. (João)

Apesar de casos de hanseníase em sua família, José fez referência como doença bíblica:

Porque isso aí eu já puxava de antigamente, que eu via pela época de Jesus, aí já sabia mais ou menos o que era hanseníase, aí quando o médico suspeitou, vou procurar para fazer um tratamento. (José)

No caso de Amélia, o fato do conhecimento de contato com pessoa com hanseníase só após início de seu tratamento, causou suspeita da fonte de contágio:

Não sabia e ninguém dizia, ninguém falava qual era o problema dela, e eu só fiquei sabendo depois quando eu tive... deve ter sido no abraço que ela me deu. (Amélia)

Sobre possível contato, Luiz reforçou a gravidade da doença sob a perspectiva religiosa:

Não, essa coisa assim nunca prestei atenção. Deus me preparou primeiro, se eu ficasse sabendo de uma doença dessa poderia estar em uma outra situação. (Luiz)

O participante João alegou nunca ter conhecido nenhuma pessoa com a doença: "Não, nunca cheguei a conhecer".

O desconhecimento sobre a hanseníase impossibilitou os participantes de reconhecer que os problemas de saúde poderiam ser uma consequência dela, demonstrando assim ausência de informação em saúde relativa ao assunto.

Para os participantes, o diagnóstico errôneo favoreceu a associação dos sinais e sintomas a outras causas. É relevante aqui recordar que Amélia teve o diagnóstico inicial como alergia e os sintomas de José foram relacionados com a doença ortopédica: 
Não dava para saber muito, tinha na mente que era alergia. (Amélia)

Não. Depois que o dermatologista falou que eu comecei a procurar. Porque até quando eu fazia o tratamento da coluna e quando tinha as feridas no pé o médico associava que era da coluna, nunca falou pode ser hanseníase. (José)

Em relação ao tempo para diagnóstico e tratamento da hanseníase, os participantes identificaram ter demorado de três a cinco anos, resultando em aumento de riscos individuais e coletivos ${ }^{18}$. No entanto, é necessário observar que tal identificação foi iluminada pelo conhecimento atual sobre a doença, atribuindo assim interpretações diferentes para suas afliçốes ${ }^{19}$.

Para Amélia restou a sensação de incapacidade e impotência, atribuindo a si a responsabilidade de seu diagnóstico tardio pelo fato de não ter dado importância aos sinais:

Fica até difícil, porque você corre em cima de uma coisa e você se sente aquela que não tem capacidade... uma pessoa impotente. Aí começou a passar na televisão, né... Aí eu falei: porque que eu não via isso, porque que eu não parava para ver? Eu também me sinto culpada, se eu tivesse dado um tempo e visto, eu ia me olhar e falar que eu estou com os mesmos sintomas...(Amélia)

Os participantes relataram sentimentos ambíguos sobre as mudanças na vida após o diagnóstico com sequelas: alívio, preocupação, sossego, normalidade, culpa, medo, sofrimento e perda de objetivos de vida.

Para Luiz, o diagnóstico trouxe sensação de sossego e diminuição da preocupação:

Eu fiquei mais sossegado. Eu estava sabendo o que é, eu estava sendo tratado. A partir do momento que você não sabe, fica com dúvida... aí acaba nos deixando preocupados, a gente fica cabisbaixo. Hoje não, eu levo de boa entendeu? (Luiz)

Após o diagnóstico, Amélia relatou dificuldade em encontrar objetivos de vida, identifica a doença como causa do seu isolamento social, na medida em que se amedronta com a possibilidade de não ser aceita pela própria família:

Mudou, eu fiquei uma pessoa [...] sem muito objetivo, quase toda hora meu marido me pega chorando [...] Só uma irmã que sabe desse problema, porque eu tenho medo de contar pros outros e não sei como é que eu vou ser aceita [...] (Amélia)

Para José, o diagnóstico trouxe alívio pela descoberta e pelo tratamento. Ele relata a importância da atitude que teve ao procurar o médico dermatologista e demonstra satisfação com o atendimento, embora ainda apresente queixas em decorrência da doença: 
Me trouxe alívio [...] descobri a doença e estou no tratamento. Se eu não tivesse [...] passado no dermatologista e ficasse esperando essa mancha sumir, ia estar um pouco pior, mas a minha trajetória de lá pra cá, depois que descobri, tá ótima [...] as dores é com o tempo. (José)

Para João, o diagnóstico e o tratamento representaram a solução, com diminuição das manchas e melhora da marcha:

Eu fiquei normal, agora é só tomar o remédio e fica bom [...] As manchas foram embora [...] só esse pé que está mais embaçado, mas mesmo ainda tá bem melhor que antes. Eu ando mais seguro, trabalho e ando bastante o dia todinho, acho que tô bem. (João)

É possível observar entre os participantes Luiz, Amélia e José a relação da hanseníase com o estigma da lepra, com incompreensão sobre a transmissão e a cura da doença.

Mantellini, Gonçalves e Padovani apontam na hanseníase a influência da perspectiva religiosa ainda nos tempos atuais. Tanto referências bíblicas como budistas criam a impressão da associação a sofredores, pecadores e criminosos ${ }^{20}$.

Para Luiz, a doença e o sofrimento são percebidos como algo merecido em decorrência dos seus atos passados:

Hoje, assim, eu tô colhendo o que plantei, a gente colhe o que planta. Se hoje eu adquiri isso, entendeu, é porque eu fiz alguma coisa. (Luiz)

Para Amélia, o diagnóstico foi devastador. Embora reconheça o apoio da equipe de saúde e alguns familiares mais próximos, prevalece o medo da revelação do diagnóstico, uma vez que a hanseníase pode ser relacionada com o estigma lepra:

Eu tenho certeza que todos aqueles que me rodeiam vão se afastar, os únicos que não se afastaram foram o meu marido e os meus filhos. Eles sabem o que eu tenho, sabem o nome da doença, mas se eu falar pra alguém ao invés de hanseníase, eu falar que é a "lepra”, eu não vou ter amizade é com mais ninguém, é cruel o negócio. (Amélia)

Para José, estigma da hanseníase pertence à cultura brasileira e gera medo:

É então, porque se tu falar uma doença e a pessoa não for um pouco mais estudada e não tiver o conhecimento da hanseníase, já se afasta [...] fica com medo [...] acho que é a cultura do brasileiro se afastar da pessoa quando sabe que tá. (José) 
Constatou-se ausência de conhecimento prévio sobre a hanseníase pelos participantes e a inabilidade dos profissionais médicos sobre os sinais e sintomas da doença, que promoveram assim diagnósticos equivocados e a consequente desqualificação das queixas e do comprometimento da autonomia para informar a condição de saúde.

A negligência em relação às necessidades de saúde se apresenta diante da dificuldade para o acesso ao diagnóstico oportuno em hanseníase. Sendo uma doença de diagnóstico sobretudo clínico nos IT analisados, percebe-se o déficit na avaliação clínica inicial e aponta-se a urgente necessidade da valorização da condição humana e social no cuidado em saúde e a observação cuidadosa dos determinantes sociais, na medida em que as desigualdades sociais dificultam o acesso aos serviços ${ }^{6,12,21}$.

Assim, as falas sobre o adoecimento e os sentimentos vivenciados durante os IT analisados são compatíveis com a observação sobre o ponto de vista do usuário e suas queixas em relação aos serviços de saúde, conforme afirma Merhy²: "[...] Os usuários, como regra, sentem-se inseguros, desinformados, desamparados, desprotegidos, desrespeitados, desprezados” (p. 3).

Estudos realizados em estados endêmicos (Bahia e Pará) citam a existência de percepçôes negativas sobre a doença e obstáculos para o diagnóstico, que apontam uma sucessão de erros diagnósticos e concluíram que o IT das pessoas com hanseníase é demorado, nebuloso e conflitante, resultado semelhante ao presente estudo ${ }^{6,23}$.

Na população colombiana, um estudo concluiu que o tempo decorrido entre o aparecimento dos primeiros sintomas e o diagnóstico constituiu um fator prognósticochave da presença das deficiências no momento do diagnóstico da hanseníase. Observou-se que quanto maior o atraso no diagnóstico, maior proporção de pacientes são diagnosticados com deficiência, tanto mulheres quanto homens ${ }^{24}$.

As barreiras de acesso aos serviços públicos de saúde impulsionam os usuários a buscar solução no serviço privado, fato observado em outras doenças, por exemplo, nas oftalmológicas, mas em caso de necessidade de cirurgias revertem as trajetórias assistenciais ao serviço público ${ }^{25}$. $\mathrm{O}$ tratamento da hanseníase é realizado exclusivamente no SUS, assim há reversão automática das trajetórias assistenciais aos serviços públicos, que contribui para o controle dos dados epidemiológicos, expondo a fragilidade do cuidado em saúde diante do diagnóstico em hanseníase.

O estudo exploratório e quantitativo realizado em três centros de referência apontou que o não reconhecimento, pelos pacientes, dos sinais e sintomas como graves e as altas taxas de diagnósticos incorretos são os principais fatores que contribuem para o atraso do diagnóstico e a transmissão contínua de hanseníase no Brasil ${ }^{26}$.

Assim, a deficiência relacionada à hanseníase é um desafio para a saúde pública e para os serviços sociais e de reabilitação em países endêmicos, devendo a informação incluir a importância do diagnóstico precoce para a prevenção de deficiências ${ }^{26,27}$. 


\section{Considerações finais}

Nos relatos apresentados, a alteração estética prevaleceu para hipótese diagnóstica de hanseníase. Percebe-se, portanto, que a hanseníase tem seu potencial incapacitante ignorado: a percepção e a relação das deficiências com a causa (ocorridas com os participantes no momento da avaliação física no serviço especializado) exacerbam os sentimentos negativos, somando-se às rupturas causadas pela experiência do adoecimento.

Do ponto de vista dos autores, o tempo e o acesso para diagnóstico e tratamento mostraram-se fator preponderante na instalação das deficiências na hanseníase, com aumento da possibilidade de transmissão da doença. O tempo e o risco caminham juntos e a demora para o diagnóstico na hanseníase potencializa os riscos individuais e coletivos, com impactos negativos no cotidiano dos sujeitos.

Porém, o tempo foi visto de forma diferente pelos participantes, desde aquele que o considerou adequado, mesmo indo a diversos serviços de saúde, até aquele que o considerou demorado, após um diagnóstico inicial errôneo com invalidação das suas queixas, demonstrando assim a singularidade da experiência do adoecimento em cada IT analisado.

Os relatos expuseram assim o descompasso entre o preconizado e o ideal ao que é realmente ofertado para o diagnóstico oportuno de hanseníase nos municípios estudados. É fato relevante o atendimento ser relegado aos serviços especializados, o que desperta a necessidade de estudos posteriores enfocando a análise das açóes de controle da doença e da articulação intersetorial da rede de Atenção à Saúde para o cuidado em hanseníase.

As revelaçôes dos intrincados itinerários terapêuticos trazem à tona como questionamento: as incapacidades são então causadas pela hanseníase ou pela fragilidade do cuidado? A proposta do estudo do IT trouxe, portanto, contribuiçóes na análise dos processos avaliativos de cunho qualitativo no SUS, contribuindo para o entendimento dos fenômenos apontados nos estudos quantitativos e epidemiológicos, bem como demonstrou a força do agir leigo mediante as iniquidades em saúde.

As incapacidades na hanseníase refletem diretamente a capacidade de diagnóstico e cuidado, os quais se impóem como desafios à integralidade da atenção. O diagnóstico tardio ressalta então a negligência das necessidades em saúde da população, o que contribui para a manutenção da hanseníase como doença incapacitante e estigmatizante.

A reflexão suscitada neste estudo sugere novas pesquisas, a fim de identificar padróes entre os fatores que contribuem para o diagnóstico tardio em hanseníase. 


\section{Contribuições dos autores}

Todos os autores participaram ativamente de todas as etapas de elaboração do manuscrito.

\section{Conflito de interesse}

Os autores não têm conflito de interesse a declarar.

\section{Direitos autorais}

Este artigo está licenciado sob a Licença Internacional Creative Commons 4.0, tipo BY (https://creativecommons.org/licenses/by/4.0/deed.pt_BR).

\section{(cc) BY}

\section{Editor}

Antonio Pithon Cyrino

Editora associada

Lina Rodrigues de Faria

\section{Submetido em}

19/09/20.

Aprovado em

$11 / 02 / 21$.

\section{Referências}

1. Diório SM. Aspectos microbiológicos e moleculares do mycobateriumleprae. In: Alves ED, Ferreira TL, Ferreira IN, organizadores. Hanseníase: avanços e desafios. Brasília: Nesprom; 2014. p. 67-80.

2. Brasil. Ministério da Saúde. Secretaria de Vigilância em Saúde. Caracterização da situação epidemiológica da hanseníase e diferenças por sexo, Brasil, 2012- 2016. Bol Epidemiol [Internet]. 2018 [citado 6 Abr 2017]; 49(4). Disponível em: https://www. saude.gov.br/images/pdf/2018/fevereiro/19/2018-004-Hanseniase-publicacao.pdf

3. Organização Mundial de Saúde. Estratégia global para hanseníase 2016-2020: acelerar a ação para um mundo sem lepra [Internet]. Genebra: OMS; 2016 [citado 6 Abr 2017]; Disponível em: https://apps.who.int/iris/bitstream/hand le/10665/208824/9789290225201-pt.pdf

4. Bassaneze B, Gonçalves A, Padovani CR. Características do processo de diagnóstico de hanseníase no atendimento primário e secundário. Diagn Tratamento. 2014; 19(2):61-7. 
5. Ferreira IN. A hanseníase no contexto das doenças negligenciadas. In: Alves ED, Ferreira TL, Ferreira IN, organizadores. Hanseníase: avanços e desafios. Brasília: Nesprom; 2014. p. 41-4.

6. Lopes VAS, Rangel EM. Hanseníase e vulnerabilidade social: uma análise do perfil socioeconômico de usuários em tratamento irregular. Saude Debate. 2014; 38(103):817-29.

7. Brasil. Ministério da Saúde. Secretaria de Vigilância em Saúde. Departamento de Vigilância das Doenças Transmissíveis. Guia prático sobre a hanseníase [Internet]. Brasília: Ministério da Saúde; 2017 [citado 8 Set 2018]. Disponível em: http:// portalarquivos2.saude.gov.br/images/pdf/2017/novembro/22/Guia-Pratico-deHanseniase-WEB.pdf

8. Santos KCB, Correa RGFC, Rolim ILTP, Pascoal, LM, Ferreira AGN. Estratégias de controle e vigilância de contatos de hanseníase: revisão integrativa. Saude Debate. 2019; 23(121):576-91.

9. Brasil. Ministério da Saúde. Coordenação geral de hanseníase e doenças em eliminação (CGHDE). Estratégia nacional para o enfrentamento da hanseníase 2016-2022 (versão preliminar) [Internet]. Brasília: Ministério da Saúde; 2016 [citado 8 Set 2018]. Disponível em: http://portalarquivos2.saude.gov.br/images/pdf/2019/marco/27/ Estrategia-Nacional-CGHDE-Consulta-Publica-27mar.pdf

10. Alves PC. Itinerário terapêutico e o nexus de significado da doença. Polit Trab Rev Cienc Soc. 2015; 1(42):29-43.

11. Cecílio LCO, Carapinheiro G, Andreazza R, organizadores. Os mapas do cuidado: o agir leigo na saúde. São Paulo: Hucitec, Fapesp; 2014.

12. Gerhardt TE. Itinerários terapêuticos em situaçóes de pobreza: diversidade e pluralidade. Cad Saude Publica. 2006; 22(11):2449-63.

13. Hespanhol MCL. Itinerário terapêutico de pessoas com hanseníase e deficiência adquirida: a análise do diagnóstico tardio [dissertação]. Santos: Universidade Federal de São Paulo; 2019.

14. Souza EA, Boigny RN, Ferreira AF, Alencar CH, Oliveira MLW, Ramos AN Jr. Vulnerabilidade programática no controle da hanseníase: padrôes na perspectiva de gênero no estado da Bahia, Brasil. Cad Saude Publica. 2018; 34(1):e00196216.

15. Cecilio LCO. As necessidades de saúde como conceito estruturante na luta pela integralidade e equidade na atenção em saúde. In: Pinheiro R, Mattos RA, organizadores. Os sentidos da integralidade na atenção e no cuidado em saúde. Rio de Janeiro: UERJ, IMS, Abrasco; 2006.

16. Ferreira JO. O corpo sígnico. In: Alves PC, Minayo MCS, organizadores. Saúde e doença: um olhar antropológico. Rio de Janeiro: Fiocruz; 1994.

17. Instituto Brasileiro de Geografia e Estatística - IBGE. Síntese de indicadores sociais: uma análise das condiçôes de vida da população brasileira: 2017. Coordenação de população e indicadores sociais [Internet]. Rio de Janeiro: IBGE; 2017 [citado 8 Set 2018]. Disponível em: https://biblioteca.ibge.gov.br/visualizacao/livros/liv101459.pdf

18. Santos L, Monteiro de Andrade LO. Acesso às ações e aos serviços de saúde: uma visão polissêmica. Cien Saude Colet. 2012; 17(11):2876-80.

19. Alves PC. A experiência da enfermidade: consideraçóes teóricas. Cad Saude Publica. 1993; 9(3):263-71.

20. Mantellini GG, Gonçalves A, Padovani CR. Incapacidades físicas em hanseníase: coisa do passado ou prioridade na prevenção? Hansenol Int. 2009; 34(2):33-9. 
21. Carneiro DF, Silva MMB, Pinheiro M, Palmeira IP, Matos EVM, Ferreira AMR. Itinerários terapêuticos em busca de diagnóstico e tratamento da Hanseníase. Rev Baiana Enferm. 2017; 3(2):e17541.

22. Merhy EE. O ato de cuidar: a alma dos serviços de saúde [Internet]. In: Brasil. Ministério da Saúde. Secretaria de Gestão do Trabalho e Educação em Saúde. Ver-SUS Brasil: cadernos de textos [Internet]. Brasília: Ministério da Saúde; 2004 [citado 6 Abr 2017]. p. 108-37. Disponível em: https://www.nescon.medicina.ufmg.br/biblioteca/imagem/2103.pdf

23. Martins PV, Iriart JAB. Itinerários terapêuticos de pacientes com diagnóstico de hanseníase em Salvador, Bahia. Physis. 2014; 24(1):273-89.

24. Guerrero MI, Muvdi S, León CI. Retraso enel diagnóstico de lepra como factorpronóstico de discapacidaden una cohorte de pacientes enColombia, 2000-2010. Rev Panam Salud Publica. 2013; 33(2):137-43.

25. Lima NC, Baptista TWF, Vargas EP. Ensaio sobre 'cegueiras': itinerário terapêutico e barreiras de acesso em assistência oftalmológica. Interface (Botucatu). 2017; 21(62):615-27.

26. Henry M, Galan N, Teasdale K, Prado R, Amar H, Rays MS, et al. Factors contributing to the delay in diagnosis and continued transmission of leprosy in Brazil - an explorative, quantitative, questionnaire based study. PLoS Negl Trop Dis. 2016; 10(3):1-12.

27. Van Brakel WH, Sihombing B, Djarir H, Beise K, Kusumawardhani L, Yulihane R, et al. Disability in people affected by leprosy: the role of impairment, activity, social participation, stigma and discrimination. Glob Health Action. 2012; 5:1-11. 
There are remarkable numbers of new leprosy cases with 2 (GIF 2) degree of physical disability, demonstrating the inefficient timely detection. This article presents case reports, based on a qualitative study, regarding four patients with Hansen's disease and a GIF 2 level at the time of diagnosis, analyzing the late diagnosis from the perspective of therapeutic itineraries (TI). The cases came from two municipalities in the Metropolitan Region of Baixada Santista: Praia Grande and São Vicente. Three men and one woman participated, between 45 and 61 years old. The researcher performed documentary analysis and in-depth interviews. Resulting data was submitted to content analysis and four thematic categories were identified: health care; body in leprosy; disabilities in leprosy; late diagnosis. The results reveal intricate therapeutic itineraries with obstacles for reaching a diagnosis. Lack of information about Hansen's disease and professional inability to diagnose increased both individual and collective risks, in addition to the negative impact on the subjects' daily lives. Thus, a late diagnosis due to the frailty of care strongly concurs to keep Hansen's disease as a stigmatizing and disabling disease.

Key words: Public health. Hansen's disease. Disabled person. Late diagnosis. Therapeutic itinerary.

Se subrayan casos nuevos de enfermedad de Hansen (lepra) con grado de discapacidad física 2 (GIF 2), que demuestran la ineficiente detección oportuna. El artículo es un relato de casos y propone analizar el diagnóstico tardío bajo la perspectiva del itinerario terapéutico (IT), con base en un estudio cualitativo. El escenario fueron dos municipios de la Región Metropolitana de la Baixada Santista: Praia Grande y São Vicente. Se realizó el análisis documental y entrevista en profundidad con cuatro participantes. El material se sometió a análisis de contenido y se definieron las categorías temáticas: cuidado de salud, cuerpo en la enfermedad de Hansen; discapacidades en la enfermedad de Hansen y diagnóstico tardío. Se revelaron intricados itinerarios terapéuticos, señalados por la fragilidad del cuidado, con error y atraso en el diagnóstico, que potencializaron los riesgos individuales y colectivos e impactaron negativamente el cotidiano de los sujetos.

Palabras clave: Salud pública. Enfermedad de Hansen. Persona con discapacidad. Diagnóstico tardío. Itinerario terapéutico. 